\title{
Experience of fatigue, and its relationship to physical capacity and disease severity in men and women with COPD
}

This article was published in the following Dove Press journal:

International Journal of COPD

12 December 2013

Number of times this article has been viewed

\section{Kristina Tödt ${ }^{1,2}$ \\ Elisabeth Skargren ${ }^{3}$ \\ Magnus Kentson ${ }^{4}$ \\ Kersti Theander ${ }^{5,6}$ \\ Per Jakobsson ${ }^{2}$ \\ Mitra Unosson}

'Department of Social and Welfare Studies, Faculty of Health Sciences Linköping University, Norrköping, Sweden; ${ }^{2}$ Department of Pulmonary Medicine, University Hospital,

${ }^{3}$ Department of Medicine and Health, Faculty of Health Sciences, Linköping University, Linköping, Sweden;

${ }^{4}$ Department of Pulmonary Medicine, Ryhov Hospital, Jönköping, Sweden; ${ }^{5}$ Department of Nursing, Faculty of Social and Life Sciences, Karlstad University, Karlstad, Sweden; ${ }^{6}$ Primary Care Research Unit, County Council of Värmland, Sweden
Correspondence: Kristina Tödt Department of Social and Welfare Studies, Faculty of Health Sciences, Linköping University, S-60 I

74 Norrköping, Sweden

Tel +46 I0 I03 3524

Fax +46 $10 \quad 1033628$

Email kristina.todt@lio.se
Introduction: Several differences have been reported in the clinical characteristics of chronic obstructive pulmonary disease (COPD) between men and women. Differences have been found in the association between respiratory symptoms and lung function, and in the factors associated with dyspnea. This raises the question of whether there are differences between the sexes in the relationship between fatigue, the second most prevalent symptom, and the variables of physical capacity and disease severity.

Objectives: To examine the experience of fatigue and its relationship to physical capacity and disease severity in men and women with COPD.

Methods: In a cross-sectional study 121 patients with COPD (54 men and 67 women), the experience of fatigue (frequency, duration, and severity) and physical capacity (lung function, 6-minute walk distance [6MWD], grip strength, and timed-stand test) were assessed. Disease severity was graded according to the Body mass index, airway Obstruction, Dyspnoea and Exercise capacity (BODE) index. Two multiple logistic regression models were tested, both of which were performed separately in men and women, to examine the association between the experience of fatigue and variables of physical capacity and the BODE index.

Results: Eighty-nine (73.6\%) patients experienced fatigue, with similar proportions in men and women. The men with fatigue had worse physical capacity and more severe disease than did the men without fatigue: for men with and without fatigue, respectively, the percent of predicted forced expiratory volume in 1 second $\left(\mathrm{FEV}_{1}\right)$ (mean [standard deviation]) was 47 (14) vs 64 (17); the 6MWD (mean [standard deviation]) was 398 (138) vs 539 (105) m; and the BODE index (median [quartile 1-3]) was $3(2-5)$ vs $1(0-1)(P<0.01)$. In women, only higher leg fatigue post-6MWD was seen among those experiencing fatigue compared with women without fatigue: for women with and without fatigue, respectively, leg fatigue (median [quartile 1-3]) was 4 (3-5) vs $2(0-3)(P<0.001)$. The regression models showed that the 6MWD and the BODE index were associated with fatigue in both men and women, but in women, leg fatigue remained an independent associate in both models.

Conclusion: Exercise capacity and disease severity were associated with fatigue in both men and women. In women, leg fatigue was strongly associated with fatigue, which warrants further investigation.

Keywords: chronic obstructive pulmonary disease, disease state, functional capacity, sex differences, symptom experience, leg fatigue

\section{Introduction}

The prevalence of chronic obstructive pulmonary disease (COPD) is increasing throughout the world, more rapidly among women than men. ${ }^{1}$ Patients with COPD suffer from several symptoms that have an adverse effect on general health and quality 
of life. ${ }^{2}$ Fatigue, the second most prevalent symptom experienced by patients with COPD, ${ }^{2,3}$ is defined as "a subjective, unpleasant symptom which incorporates total body feelings ranging from tiredness to exhaustion, creating an unrelenting overall condition which interferes with individuals' ability to function to their normal capacity."4 Fatigue is associated with functional limitations in daily living, poor health, and hospitalization. ${ }^{5-8}$ One dimension of functional status is physical capacity, which refers to the individual's maximum potential, expressed in terms of, for example, lung function, exercise capacity, and muscle strength. ${ }^{9}$ In patients with COPD, fatigue is moderately related to exercise capacity, ${ }^{7,10,11}$ but the relationship between fatigue and lung function is contradictory. ${ }^{3,10-14}$ In patients with severe COPD, fatigue is related to muscle strength in both the upper and lower limbs. ${ }^{12}$ The multidimensional grading of disease severity, the Body mass index, airway Obstruction, Dyspnoea and Exercise capacity (BODE) index, ${ }^{15}$ includes not only lung function and exercise capacity but also, dyspnea and body mass index, and yet the relationship between fatigue and the BODE index is not clear. ${ }^{7,16}$ There are several differences in the clinical expression of the disease between men and women. ${ }^{17}$ Different studies have reported that women have lower exercise capacity than men ${ }^{18,19}$ and seem to be more prone to impaired thigh muscle function, ${ }^{20}$ suggesting a stronger relation between fatigue and physical capacity. The variables assessing and defining physical capacity are used as a primary outcome in pulmonary rehabilitation. ${ }^{21}$ With the purpose of improving rehabilitation strategies among men and women with COPD, we wondered whether the relationship between experience of fatigue and physical capacity is similar in men and women.

Other studies have reported that respiratory symptoms, such as wheezing, dyspnea, and coughing, are related to lung function in men but not in women ${ }^{22}$ and that respiratory factors explain most of the variation in dyspnea in men, but not in women, with COPD. ${ }^{23}$ Consequently, there seem to be differences between men and women in regard to the factors associated with dyspnea, and this raises the question of whether there are differences in the relationship between fatigue and physical capacity, and fatigue and disease severity, in men and women with COPD. If such differences exist, this may have clinical implications for the design of rehabilitation programs. Therefore, the main purpose of this study was to examine the relationship between the experience of fatigue and factors of physical capacity and disease severity separately in men and women with COPD.

\section{Materials and methods}

\section{Patients}

This cross-sectional study included 121 patients with COPD, recruited from two outpatient clinics at one university hospital (University Hospital Linköping, Sweden) and one county hospital (Ryhov Hospital, Jönköping, Sweden). The inclusion criteria were a diagnosis of COPD and a ratio of postbronchodilator forced expiratory volume in 1 second $\left(\mathrm{FEV}_{1}\right)$ to forced vital capacity $(\mathrm{FVC})$ of $<0.70$. In addition, the patients had to be in a clinically stable condition with no change in medication in the previous 4 weeks. Patients were excluded if they had any other lung disease, cancer in the previous 5 years, known inflammatory disease (eg, rheumatoid arthritis, inflammatory bowel disease, etc), multiple sclerosis, stroke, severe ischemic heart disease, severe kidney dysfunction, insulin-dependent diabetes, or psychosocial or physical difficulties that might interfere with the assessments. In total, 198 patients who had visited the two outpatient clinics during the previous year were invited to participate by letter. Forty-six patients declined to participate, 22 were excluded, eight could not be reached, and one did not show up at the appointment. There were no differences in the age or sex distribution between the participating patients and nonparticipating patients.

The study was performed in accordance with the ethical principles for medical research involving human subjects outlined in the Declaration of Helsinki and was approved by the regional ethical review board, Linköping, Sweden. All patients gave informed consent prior to any study-related procedures.

\section{Assessments}

\section{Fatigue}

The experience of fatigue was assessed with three slightly revised structured questions that had previously been used with Swedish patients with COPD. ${ }^{24,25}$ The frequency of fatigue for the past month was scored as $0=$ not a problem, $1=1-7$ days/month, $2=8-14$ days $/$ month, $3=15-21$ days/month, or 4=22-30 days/month or every day of the month; the duration of fatigue as $0=$ no experience, $1=$ less than 6 hours/day, 2=6-12 hours/day, or $3=$ more than 12 hours/day; and the severity of fatigue as $0=$ not a problem, $1=$ one of my less severe symptoms, or $2=$ one of my worst symptoms. Cronbach's alpha for the three questions was 0.79 in the present study. The fatigue total score for frequency, duration, and severity (range 0-9) was calculated. Convergent validity was evaluated by using one item in the Memorial Symptom Assessment Scale ${ }^{26}$ (measuring the frequency, severity, and distress of lack of energy), with a 
possible total score ranging between 2-12. The Spearman's correlation coefficient between the dimensions of fatigue and lack of energy was 0.436 for frequency and was 0.465 for severity, and for the total scores of items, it was 0.658 (all $P<0.001$ ).

\section{Physical capacity}

Physical capacity included assessments of lung function, exercise capacity, and muscle strength in both the upper and lower extremities.

A postbronchodilator $(0.6 \mathrm{mg}$ of salbutamol metered-dose aerosol) dynamic lung function test $\left(\mathrm{FEV}_{1}\right.$ and $\left.\mathrm{FVC}\right)$ was performed (MasterScreen Pneumo; CareFusion, Hoechberg, Germany) in accordance with American Thoracic Society (ATS)/European Respiratory Society standards.$^{27}$ The normative values from Hedenstrom et al ${ }^{28,29}$ were used to calculate the $\mathrm{FEV}_{1} \%$ predicted and $\mathrm{FVC} \%$ predicted. The patients were classified according to the Global Initiative for Chronic Obstructive Lung Disease (GOLD) staging system. ${ }^{30}$

Exercise capacity was assessed with a duplicate 6-minute walk distance test (6MWD), in accordance with the ATS guidelines. ${ }^{31}$ The longest 6MWD was used in the analysis. For reference values, the equation developed by Troosters et al was used to calculate the $6 \mathrm{MWD} \%$ predicted. ${ }^{32}$ In addition, during the test, oxygen saturation was measured with a pulse oximeter (Nonin PalmSat ${ }^{\circledR} 2500$; Nonin Medical Inc, Minneapolis, MN, USA), and perceived dyspnea and leg fatigue before and immediately after the test were scored using the Borg Category Ratio-10 scale. ${ }^{33}$ Breathing frequency was registered.

The muscle strength of the upper extremities was measured in the dominant hand, using a Grippit ${ }^{\circledR}$ (AB Detektor; Göteborg, Sweden). Grip force was registered for 10 seconds and expressed in newtons $(\mathrm{N})$. The peak value out of three trials was used in the analysis. This method is considered to be reliable and valid..$^{34}$ The muscle strength of the lower extremities was assessed with the timed-stand test (TST), ${ }^{35}$ which measures the time in seconds (to the nearest 0.1 second) for ten stand ups from a chair to a standardized height $(45 \mathrm{~cm})$. The test is considered to be reliable and valid. ${ }^{35}$

\section{Disease severity}

Disease severity was determined according to the criteria of the multidimensional grading system, the BODE index. The BODE index includes body mass index (BMI), airway obstruction as measured by $\mathrm{FEV}_{1} \%$ predicted, dyspnea measured by the Medical Research Council (MRC) dyspnea scale, ${ }^{36}$ and exercise capacity measured as $6 \mathrm{MWD}$. The
BODE index ranges between 0 and 10, with a higher score indicating more serious disease..$^{15}$

\section{Body mass index}

Height $(\mathrm{cm})$ was measured with a stadiometer to the nearest $0.5 \mathrm{~cm}$, and weight $(\mathrm{kg})$ was measured to the nearest $0.1 \mathrm{~kg}$, without shoes and with light clothing (SECA scale Class (111) model 701 and 959; SECA GmbH \& Co. KG, Hamburg, Germany). BMI was calculated $=\mathrm{kg} / \mathrm{m}^{2}$ and categorized into four groups: $<21=$ underweight; $21-24.9=$ normal range; 25.0-29.9 = overweight; or $\geq 30=$ obesity.

\section{Demographic data and perception of general health}

Structured questionnaires covered demographic data (age, marital status, and employment), smoking history, and health. Perception of general health was assessed with two questions from the Brief Health Information appendix in the International Classification of Functioning, Disability and Health check list (ICF-checklist), which asked about perceived mental and emotional health and physical health during the past month, rated on a five-point scale from $1=$ very bad health to $5=$ very good health. ${ }^{37}$

\section{Procedure}

Approximately 1 week after the invitation letter was sent, the patients were phoned to provide them with additional information, and their current health status was updated. Those who met the inclusion criteria and gave verbal informed consent were scheduled for an appointment at the outpatient clinic. The questionnaires were sent, along with the letter giving the time of the appointment. The participants were instructed to fill in the questionnaires the day before the appointment, and their responses were checked at the appointment to avoid missing answers. All other assessments were performed at the outpatient clinics in the morning, in a standardized order and with an appropriate amount of time between the assessments of physical capacity.

The data were collected between January 2007 and September 2009.

\section{Analysis}

Normally distributed data were presented as mean and standard deviation, and skewed data as median and 25th-75th percentiles (quartiles 1-3). The differences between men and women and between patients with and without fatigue were analyzed with an independent sample $t$-test, a Mann-Whitney $U$ test, a chi-square, or Fisher's exact test as appropriate. 
Partial correlation analysis, adjusted for sex, was performed to investigate the relationship between the absence and presence of fatigue and the variables of physical capacity, oxygen saturation, dyspnea, leg fatigue, and breathing frequency immediately after the 6MWD and disease severity. Finally, two models of backward logistic regression analysis were performed with men and women separately with the purpose of analyzing the association of the variables of physical capacity (first model) and disease severity (second model) with the experience of fatigue. The dependent variable in both models was experience of fatigue, coded as $1=$ presence of fatigue or $0=$ absence of fatigue. The independent variables in the first model were the variables of physical capacity significantly correlated with fatigue $\left(\mathrm{FEV}_{1} \%\right.$ predicted, 6MWD, and leg fatigue post-6MWD). TST and grip strength were inserted, in line with findings in the literature..$^{10,12,20}$ In the second model, the independent variables were the BODE index and the variables of physical capacity not included in the BODE index (leg fatigue post-6MWD, TST, and grip strength). Both models were adjusted for age and current smoking ( $1=$ current smoker and $0=$ not a current smoker). In additional analysis, we adjusted all models with the variable "mental and emotional health," to control for its association with experience of fatigue. Values were presented with odds ratio (OR) and 95\% confidence interval (CI).

The significance level was set at $P \leq 0.05$. The data were analyzed using SPSS 19 software version (IBM Corp, Armonk NY, USA).

\section{Results}

\section{Background characteristics}

Of the 121 patients, 54 (45\%) were men and 67 (55\%) were women. The patients were predominantly classified as stages $2(36 \%)$ or $3(46 \%)$, according to the GOLD stage system. ${ }^{30}$ Similar proportions of men (87\%) and women (77\%) were in stages 2 or 3 (Table 1). Comparing sex, the females had a shorter 6MWD and lower 6MWD $\%$ predicted, needed more time to perform the TST, and had lower grip strength than the men (Table 1). No differences were found between the men and women in age, smoking status, lung function, dyspnea, BMI, mental or physical health, or disease severity according to the BODE index or the GOLD classification (Table 1).

\section{Experience of fatigue and the association between fatigue and physical capacity and disease severity}

Eighty-nine patients reported experiencing fatigue during the previous month, and 32 (26.4\%) had no experience of fatigue.
There were no statistically significant differences between men and women with regard to the prevalence or frequency, duration, and severity of fatigue (Table 2).

Men with fatigue had significantly worse physical capacity with regard to lung function, 6MWD, and TST compared with men without fatigue. In contrast to the men, women with fatigue only had higher subjective leg fatigue post-6MWD compared with women without fatigue (Table 3).

The physical capacity variables $\mathrm{FEV}_{1} \%$ predicted, $\mathrm{FVC} \%$ predicted, 6MWD, leg fatigue post-6MWD, and the BODE index correlated significantly with the experience of fatigue, controlled for sex $r=-0.224,-0.263,-0.304,0.289$, and 0.342 respectively, $(P$-values between 0.015 and $<0.001)$.

In the first multiple logistic regression model, the significantly associated variables with the experience of fatigue were 6MWD in men, and 6MWD and leg fatigue post6MWD in women (Table 4). In the second model, the BODE index in men and women and leg fatigue post-6MWD in women were significantly associated with the experience of fatigue (Table 5). Regression models additionally adjusted for mental and emotional health showed that the variables of physical capacity associated with experience of fatigue were the $\mathrm{FEV}_{1} \%$ predicted in men (OR $=0.93$; CI: $\left.0.87-0.98\right)$, and 6MWD and leg fatigue post-6MWD in women ( $[\mathrm{OR}=0.99$; CI: 0.98-1.0] and [OR =2.93; CI: 1.50-5.72], respectively). In the second model, the BODE index remained independently associated with the experience of fatigue in men (OR =3.97; CI: 1.60-9.86), and in women, only leg fatigue was associated with fatigue ( $\mathrm{OR}=2.37$; CI: 1.38-4.09).

\section{Discussion}

The main findings of this study were that the experience of fatigue was common and that the experience of fatigue was associated with both exercise capacity and severity of the disease in both men and women. Furthermore, subjective leg fatigue after 6MWD was found to be strongly associated with the experience of fatigue in women.

The results showed that nearly three-quarters of the patients with stable COPD experienced fatigue. The lack of difference between men and women in the presence of fatigue as well as in the frequency, duration, and severity of fatigue is in line with previous findings. ${ }^{25}$ In this study, fatigue was assessed as a symptom and conceptualized as a multidimensional experience including timing (frequency and duration) and severity (or intensity). ${ }^{38}$ This assessment of the experience of fatigue considers the symptom itself rather than the impact of fatigue on different functions. ${ }^{38}$ Furthermore, a high correlation has been found between symptom and impact scores. ${ }^{39}$ The three structured questions 
Table I Differences between men and women with chronic obstructive pulmonary disease

\begin{tabular}{|c|c|c|c|}
\hline & Men $(n=54)$ & Women $(n=67)$ & $P$-value \\
\hline \multicolumn{4}{|l|}{ Background characteristics } \\
\hline Mean age (SD), years & $67.6(6.8)$ & $66.5(7.5)$ & 0.425 \\
\hline \multicolumn{4}{|l|}{ Smoking status, n (\%) } \\
\hline Current & $13(24)$ & $2 I(3 I)$ & 0.600 \\
\hline Former & $40(74)$ & $44(66)$ & \\
\hline Never & $I(2)$ & $2(3)$ & \\
\hline \multicolumn{4}{|l|}{ Smoking history } \\
\hline Pack-yr, mean (SD) & $36.7(19.5)$ & $30.5(18)$ & 0.076 \\
\hline Dyspnea MRC-scale, median (QI-3) & $2(1-3)$ & $2(1-3)$ & 0.126 \\
\hline $\mathrm{BMI}, \mathrm{kg} / \mathrm{m}^{2}$, mean $(\mathrm{SD})$ & $26.2(5.3)$ & $27.4(6.8)$ & 0.263 \\
\hline Underweight, BMI <2I.0, n (\%) & $8(15)$ & $12(18)$ & 0.042 \\
\hline Normal weight, BMI =21.0-24.9, n (\%) & $16(30)$ & $20(30)$ & \\
\hline Overweight BMI =25.0-29.9, n (\%) & $19(35)$ & $10(15)$ & \\
\hline Obesity, BMI $\geq 30.0, \mathrm{n}(\%)$ & II (20) & $25(37)$ & \\
\hline \multicolumn{4}{|l|}{ Physical capacity } \\
\hline \multicolumn{4}{|l|}{ Lung function, mean (SD) } \\
\hline $\mathrm{FEV}, \%$ predicted & $50.8(16.8)$ & $48.6(15.7)$ & 0.451 \\
\hline FVC\% predicted & $86.6(16.8)$ & $85(17.9)$ & 0.615 \\
\hline $\mathrm{FEV} / \mathrm{FVC}$ & $0.43(0.12)$ & $0.44(0.1)$ & 0.652 \\
\hline \multicolumn{4}{|l|}{ Exercise capacity } \\
\hline 6MWD (meter), mean (SD) & $432(144)$ & $380(128)$ & 0.038 \\
\hline 6MWD\% predicted, mean (SD) & $76.9(23.9)$ & $67(20.8)$ & 0.017 \\
\hline $\mathrm{SaO}_{2}$ post-6MWD, mean (SD) & $88.9(5.8)$ & $88.8(5.6)$ & 0.884 \\
\hline Dyspnea post-6MWD, median (QI-3) & $4(3-5)$ & $4(3-5)$ & 0.459 \\
\hline Leg fatigue post-6MWD, median (QI-3) & $3(I-4.12)$ & $3(2-5)$ & 0.285 \\
\hline BF post-6MWD, mean (SD) & $27.7(6.0)$ & $29.6(5.9)$ & 0.087 \\
\hline \multicolumn{4}{|l|}{ Muscle strength, median (QI-3) } \\
\hline TST (seconds) & $22.4(18.2-33.7)$ & $27.5(22.7-34.3)$ & 0.022 \\
\hline Grip strength (N) & $368(292-442)$ & $190(159-245)$ & $<0.001$ \\
\hline \multicolumn{4}{|l|}{ Health } \\
\hline Mental and emotional health, median (QI-3) & $4(3-4)$ & $3(3-4)$ & 0.345 \\
\hline Physical health, median (QI-3) & $3(2-4)$ & $3(2-3)$ & 0.994 \\
\hline \multicolumn{4}{|l|}{ Disease severity, n (\%) } \\
\hline GOLD stage I & I (2) & $5(8)$ & 0.148 \\
\hline GOLD stage 2 & $25(46)$ & $19(28)$ & \\
\hline GOLD stage 3 & $22(4 I)$ & $33(49)$ & \\
\hline GOLD stage 4 & $6(11)$ & $10(15)$ & \\
\hline BODE index, median (QI-3) & $3(1-4.25)$ & $3(2-5)$ & 0.153 \\
\hline
\end{tabular}

Notes: $P$-values were tested by independent sample $t$-test where the variable is stated as a mean (SD); by $\chi^{2}$ test where the variable is given as number (\%); and by the Mann-Whitney $U$ test where the variable is given as median (QI-3).

Abbreviations: 6MWD, 6-minute walk distance; BF, breathing frequency per minute; BMI, body mass index; BODE index, multidimensional index (B, body mass index; $\mathrm{O}$, airway Obstruction; D, dyspnoea; E, exercise capacity); FEV , forced expiratory volume in I second; FVC, forced vital capacity; GOLD, the Global Initiative for Chronic Obstructive Lung Disease; MRC-dyspnea, Medical Research Council dyspnea scale; Pack-yr, number of years smoking times average number of cigarettes smoked per day divided by 20; $\mathrm{Q}$, quartile; $\mathrm{SaO}_{2}$, oxygen saturation; SD, standard deviation; TST, timed-stands test.

for fatigue in this study showed acceptable convergent validity with the item "lack of energy" included in the Memorial Symptom Assessment Scale.

Our study showed that the women had lower exercise capacity and muscle strength than men. These differences are probably partly related to constitutional differences, but the lower exercise capacity in women was seen both in absolute values and in 6MWD\% predicted, adjusted for height, age, weight, and sex. Several other studies have also shown that women with COPD have lower exercise capacity and more respiratory symptoms, even though they have better preserved lung function than men. ${ }^{18,19,40}$ The reasons for these differences are not clear. ${ }^{17}$

The men who experienced fatigue had worse physical capacity in all the areas covered and worse disease severity, according to the BODE index, than did the men who did not experience fatigue. The findings for the men are in line with previous studies using mixed samples. ${ }^{7,10,11}$ In contrast with this, the women in the present study with experience of fatigue had impairment in lung function, exercise capacity, and muscle strength comparable to that in women without fatigue. Moreover, there was no significant difference in 
Table 2 The experience of fatigue in men and women with COPD

\begin{tabular}{|c|c|c|c|}
\hline & $\begin{array}{l}\text { Men } \\
(n=54)\end{array}$ & $\begin{array}{l}\text { Women } \\
(n=67)\end{array}$ & $P$-value \\
\hline Prevalence, n (\%) & $4 \mid(76)$ & $48(72)$ & 0.680 \\
\hline Fatigue frequency, n (\%) & & & 0.265 \\
\hline Not a problem & $13(24)$ & $19(28)$ & \\
\hline I-7 days/month & $13(24)$ & $11(16)$ & \\
\hline 8-14 days/month & $5(9)$ & $2(3)$ & \\
\hline$|5-2|$ days/month & $5(9)$ & $4(6)$ & \\
\hline$\geq 22$ days/month & $18(33)$ & $31(46)$ & \\
\hline Fatigue duration, n (\%) & & & 0.593 \\
\hline No experience & $13(24)$ & $19(28)$ & \\
\hline$<6 \mathrm{~h} /$ day & $24(44)$ & $22(33)$ & \\
\hline $6-12 \mathrm{~h} /$ day & $10(19)$ & $17(25)$ & \\
\hline 12-24 h/day & $7(13)$ & $9(13)$ & \\
\hline Fatigue severity, n (\%) & & & 0.433 \\
\hline Not a problem & $19(35)$ & $2 I(3 I)$ & \\
\hline One of my less severe symptoms & $20(37)$ & $20(30)$ & \\
\hline One of my worst symptoms & $15(28)$ & $26(39)$ & \\
\hline Fatigue total score, median (Q $\mathrm{I}-3$ ) & $4(1.5-7)$ & $6(0-8)$ & 0.428 \\
\hline
\end{tabular}

disease severity between the women with and without fatigue. Except for a significantly higher subjective leg fatigue in women with fatigue, these findings suggest that the experience of fatigue among women may be related to factors other than physical capacity or disease severity. However, the result of the first regression analysis showed that exercise capacity was independently associated with fatigue in both men and women. This indicates that there is a link between the experience of fatigue and exercise capacity in women as well. Neither lung function nor muscle strength remained as independent associates. The latter could be explained by the fact that the 6MWD as a measure of exercise capacity is an outcome of the global and integrated responses of all the systems involved during exercise, including the cardiopulmonary system, peripheral circulation, and muscle metabolism. ${ }^{31}$

Our finding of higher leg fatigue among the women with fatigue even though they had similar 6MWD and dyspnea scores to women without experience of fatigue suggests that limitations within the working muscle, ie, muscle

Table 3 Comparison between patients with and without fatigue in men and women with chronic obstructive pulmonary disease

\begin{tabular}{|c|c|c|c|c|c|c|}
\hline & \multicolumn{2}{|l|}{ Men } & \multirow[t]{2}{*}{$P$-value } & \multicolumn{2}{|l|}{ Women } & \multirow[t]{2}{*}{$P$-value } \\
\hline & $\begin{array}{l}\text { No fatigue } \\
(n=\mid 3)\end{array}$ & $\begin{array}{l}\text { Fatigue } \\
(n=4 I)\end{array}$ & & $\begin{array}{l}\text { No fatigue } \\
(n=19)\end{array}$ & $\begin{array}{l}\text { Fatigue } \\
(n=48)\end{array}$ & \\
\hline Age, years, mean (SD) & $67.8(6.3)$ & $67.5(7.0)$ & 0.87 & $68.9(6.1)$ & $65.6(7.8)$ & 0.103 \\
\hline \multicolumn{7}{|l|}{ Physical capacity } \\
\hline $\mathrm{FEV}, \%$ predicted, mean (SD) & $64.2(17.2)$ & $46.6(14.5)$ & 0.001 & $49.5(12.8)$ & $48.3(16.8)$ & 0.779 \\
\hline FVC\% predicted, mean (SD) & $96(19.1)$ & $82.8(15.1)$ & 0.002 & $89.1(13.3)$ & $83.4(19.3)$ & 0.241 \\
\hline $\mathrm{FEV}_{\mathrm{I}} / \mathrm{FVC}$, mean (SD) & $0.48(0.11)$ & $0.42(0.12)$ & 0.08 & $0.43(0.09)$ & $0.45(0.11)$ & 0.541 \\
\hline 6MWD (meter), mean (SD) & $539(105)$ & $398(138)$ & 0.001 & $416(104)$ & $365(134)$ & 0.148 \\
\hline 6MWD\% predicted, mean (SD) & $96.9(14)$ & $70.6(23.1)$ & $<0.001$ & $74.6(17.5)$ & $64(2 \mid .5)$ & 0.059 \\
\hline $\mathrm{SpO}_{2}$ post-6MWD, mean (SD) & $91.4(4.3)$ & $88.1(6.1)$ & 0.081 & $87.3(5.3)$ & $89.4(5.7)$ & 0.184 \\
\hline Dyspnea post-6MWD, median (QI-3) & $3(3-4.5)$ & $4(3.5-5.5)$ & 0.068 & $4(3-5)$ & $4(3-5)$ & 0.386 \\
\hline Leg fatigue post-6MWD, median (QI-3) & $3(1.5-4)$ & $3(I-5)$ & 0.565 & $2(0-3)$ & $4(3-5)$ & $<0.001$ \\
\hline BF post-6MWD, mean (SD) & $25.2(6.3)$ & $28.6(5.8)$ & 0.083 & $29.6(5.7)$ & $29.7(6.1)$ & 0.950 \\
\hline TST (seconds), median (QI-3) & $20.1(14.7-23.6)$ & $23.7(18.7-35.5)$ & 0.017 & $27.5(22.7-34.3)$ & $32.1(22.2-35.1)$ & 0.988 \\
\hline Grip strength (N), median (Q I-3) & $422(365-476)$ & $336(276-420)$ & 0.052 & $190(159-245)$ & $188(\mid 44-248)$ & 0.640 \\
\hline BMI kg/m², mean (SD) & $27.1(4.6)$ & $25.9(5.5)$ & 0.477 & $25.7(4.6)$ & $28.1(7.4)$ & 0.122 \\
\hline Underweight, BMI <21.0, n (\%) & 0 & $8(20)$ & 0.064 & $3(16)$ & $9(19)$ & 0.262 \\
\hline Normal weight, BMI $=21.0-24.9, \mathrm{n}(\%)$ & $4(3 I)$ & $12(29)$ & & $9(47)$ & II (23) & \\
\hline Overweight, BMI $\geq 25.0-29.0, \mathrm{n}(\%)$ & $8(62)$ & II (27) & & $2(10)$ & $8(17)$ & \\
\hline Obesity, BMI $\geq 30.0, \mathrm{n}(\%)$ & I (8) & $10(24)$ & & $5(26)$ & $20(42)$ & \\
\hline Dyspnea MRC-scale, median (QI-3) & $I(0-1)$ & $2(I-3)$ & $<0.001$ & $2(I-2)$ & $2(I-3)$ & 0.130 \\
\hline BODE index, median (QI-3) & $I(0-1)$ & $3(2-5)$ & $<0.001$ & $3(2-4)$ & $3.5(2-5)$ & 0.213 \\
\hline Mental and emotional health, median ( $\mathrm{Q} \mathrm{I}-3)$ & $4(4-5)$ & $3(3-4)$ & 0.001 & $4(4-5)$ & $3(3-4)$ & $<0.00$ I \\
\hline Physical health, median (QI-3) & $4(3-4)$ & $3(2-3)$ & $<0.001$ & $4(3-4)$ & $3(2-3)$ & $<0.001$ \\
\hline
\end{tabular}

Notes: $P$-values were tested by independent sample $t$-test where a mean (SD) is given; by Mann-Whitney $U$ test where the variable is given as a median $(\mathrm{Q} I-3)$; and by $\chi^{2}$ test where the variable is presented in numbers.

Abbreviations: 6MWD, 6-minute walk distance; BF, breathing frequency/minute; BMI, body mass index; BODE index, multidimensional index (B, body mass index; O, airway Obstruction; D, dyspnoea; E, exercise capacity); FEV , forced expiratory volume in I second; FVC, forced vital capacity; MRC, Medical Research Council; Q, quartile; SD, standard deviation; $\mathrm{SpO}_{2}$, percentage of oxygen saturation; TST, timed-stand test. 
Table 4 The physical capacity variables associated with the experience of fatigue, by sex, from multiple logistic regressions, adjusted for age and current smoking

\begin{tabular}{|c|c|c|c|c|c|c|c|c|c|}
\hline \multirow{2}{*}{$\begin{array}{l}\text { Independent } \\
\text { variables retained } \\
\text { in last step }\end{array}$} & \multicolumn{4}{|c|}{ Experience of fatigue (men, $n=53$ ) } & \multirow{2}{*}{$\begin{array}{l}\text { Independent } \\
\text { variables retained } \\
\text { in last step }\end{array}$} & \multicolumn{4}{|c|}{ Experience of fatigue (women, $n=64$ ) } \\
\hline & B & Wald & $P$-value & OR $(95 \% \mathrm{Cl})$ & & B & Wald & $P$-value & OR $(95 \% \mathrm{Cl})$ \\
\hline \multirow[t]{2}{*}{ 6MWD } & -0.017 & 8.89 & 0.003 & $0.98(0.97-0.99)$ & 6MWD & -0.01 & 8.49 & 0.004 & $0.99(0.98-1.0)$ \\
\hline & & & & & Leg fatigue post-6MWD & 0.85 & 10.83 & 0.001 & $2.33(1.40-3.87)$ \\
\hline Constant & 21.2 & & & & Constant & 9.97 & & & \\
\hline
\end{tabular}

Note: The dependent variable in this analysis was the experience of fatigue, coded so that $0=$ absence of fatigue and $\mathrm{I}=$ presence of fatigue. $\mathrm{B}$ is the regression coefficient and Wald is the Wald statistic.

Abbreviations: 6MWD, 6-minute walk distance; $\mathrm{Cl}$, confidence interval; OR, odds ratio.

fatigue, may influence the general experience of fatigue in women. Pathophysiological changes within the muscle is one of several proposed reasons for experience of fatigue in chronic illness ${ }^{41}$ but why this would be more pronounced in women alone is hard to explain. Skeletal muscle dysfunction (reduced muscle strength and endurance and increased muscle fatigability) is a central contributor to the limitations in exercise capacity seen in patients with COPD,${ }^{42}$ but there have been few comparisons of skeletal muscle dysfunction in men and women. Higher muscle fatigue in COPD patients may be due to lower levels of high-energy phosphates, lower mitochondrial density, early lactacidemia, or reduced muscle perfusion. ${ }^{43}$ However, in men and women with COPD with similar exercise capacity, no differences have been found in fiber type composition, mitochondrial density, and muscle enzyme activities in the quadriceps femoris muscle. ${ }^{44}$ On the other hand, Janaudis-Ferreira et $\mathrm{al}^{20}$ found more pronounced thigh muscle dysfunction, including muscle fatigue, among women than among men with COPD. This suggests that there are sex-related differences in the peripheral muscle dysfunction, which may influence the experience of fatigue in women. Inactivity is an important cause of the skeletal muscle dysfunction seen in patients with COPD. ${ }^{42}$ As far as we are aware, it is not known whether there are differences in the level of physical activity between men and women with COPD that could, in turn, explain differences in skeletal dysfunction. However, women seem to change their activity and particularly, to reduce their involvement in heavier tasks, such as vacuuming and making beds, to a greater extent than men. ${ }^{45}$

Endurance exercise training is related to the reduced experience of fatigue. ${ }^{46}$ The results of our research on the association between exercise capacity and the experience of fatigue in both men and women suggest that endurance exercise training might influence the experience of fatigue in both men and women. Additionally in women, specific muscle endurance training with many repetitions and low loads to improve leg fatigue might have an impact on the general experience of fatigue. However, our findings warrant further investigation using more sophisticated methods to assess muscle strength and muscle fatigue to confirm the association between leg fatigue and the experience of fatigue in women.

The result of the second regression model showed that the BODE index was independently associated with fatigue in both men and women, but in women, leg fatigue again was strongly associated with fatigue. Watson et al, found that respiratory symptoms (wheeze, dyspnea, cough, and phlegm) were good predictors of the disease state in men only. ${ }^{22}$ Our finding that the BODE index alone was independently associated with fatigue in the men suggests that the experience

Table 5 The BODE index and physical variables not included in the BODE index associated with the experience of fatigue, by sex, from multiple logistic regressions, adjusted for age and current smoking

\begin{tabular}{|c|c|c|c|c|c|c|c|c|c|}
\hline \multirow{2}{*}{$\begin{array}{l}\text { Independent } \\
\text { variables retained } \\
\text { in last step }\end{array}$} & \multicolumn{4}{|c|}{ Experience of fatigue (men, $n=53$ ) } & \multirow{2}{*}{$\begin{array}{l}\text { Independent } \\
\text { variables retained } \\
\text { in last step }\end{array}$} & \multicolumn{4}{|c|}{ Experience of fatigue (women, $n=64$ ) } \\
\hline & B & Wald & $P$-value & OR $(95 \% \mathrm{Cl})$ & & B & Wald & $P$-value & OR $(95 \% \mathrm{Cl})$ \\
\hline BODE index & 1.31 & 8.22 & 0.004 & $3.71(1.51-9.10)$ & BODE index & 0.437 & 5.38 & 0.020 & $1.56(1.07-2.24)$ \\
\hline TST & 0.13 & 2.39 & 0.122 & $1.14(0.97-1.35)$ & Leg fatigue post-6MWD & 0.783 & 10.54 & 0.001 & $2.19(1.36-3.51)$ \\
\hline Constant & 2.84 & & & & Constant & 0.696 & & & \\
\hline
\end{tabular}

Notes: The dependent variable in this analysis was the experience of fatigue, coded so that $0=$ absence of fatigue and $I=$ presence of fatigue. $B$ is the regression coefficient and Wald is the Wald statistic.

Abbreviations: 6MWD, six minute walk distance; BODE index, multidimensional index (B, body mass index; O, airway Obstruction; D, dyspnoea; E, exercise capacity); Cl, confidence interval; OR, odds ratio; TST, timed-stand test. 
of fatigue might mirror the disease state more fully in men than in women.

In our study, mental and emotional health was reported to be worse among the men and women with fatigue compared with those without fatigue. Fatigue is known to be related to mood and mental state as well as to other symptoms..$^{3,5,47}$ However, even when we adjusted the regression models for mental and emotional health, the main results did not change.

\section{Limitations of the study}

Besides the cross-sectional study design, another limitation of this study is the sample selection, which excluded patients with pronounced comorbidity. However, this made our sample more homogenous. The included patients were predominantly in stages 2 and $3(82 \%)$ of disease, and the result should be cautiously interpreted for patients in stages 1 and 4. Another reason for caution is that nearly one-quarter of the invited patients refused to participate. Those patients were not assessed for any other variables except for age and gender. Although no significant differences were found between the participants and nonparticipants with regard to age and sex, other differences that might be important for data interpretation could not be evaluated. Finally, other reasons for the sensation of leg fatigue in women (eg, venous or arterial deficiencies) were not assessed.

In conclusion, exercise capacity and disease severity were associated with fatigue in both men and women. In women, leg fatigue was strongly associated with the experience of fatigue, and this warrants further investigation.

\section{Author contributions}

All listed authors meet the criteria for authorship outlined by the International Committee for Medical Journal Editors. All authors were involved in the design of the study and approved the final version to be published. All authors engaged in the analyzing and interpretation of data, performed a critical revision of the manuscript, and are accountable for its accuracy.

\section{Acknowledgments}

The study was supported by the Swedish Heart Lung Foundation, Medical Research Council of Southeast Sweden and the Swedish Heart and Lung Association, without their involvement in the design or conduct of the study. Special thanks go to Elisabeth Häggkvist for assistance in data collection and to Elisabeth Wilhelm for statistical support.

\section{Disclosure}

The authors report no conflicts of interest in this work.

\section{References}

1. Mannino DM, Homa DM, Akinbami LJ, Ford ES, Redd SC. Chronic obstructive pulmonary disease surveillance - United States, 1971-2000. MMWR Surveill Summ. 2002;51(6):1-16.

2. Guyatt GH, Berman LB, Townsend M, Pugsley SO, Chambers LW. A measure of quality of life for clinical trials in chronic lung disease. Thorax. 1987;42(10):773-778.

3. Kapella MC, Larson JL, Patel MK, Covey MK, Berry JK. Subjective fatigue, influencing variables, and consequences in chronic obstructive pulmonary disease. Nurs Res. 2006;55(1):10-17.

4. Ream E, Richardson A. Fatigue in patients with cancer and chronic obstructive airways disease: a phenomenological enquiry. Int $J$ Nurs Stud. 1997;34(1):44-53.

5. Lewko A, Bidgood PL, Garrod R. Evaluation of psychological and physiological predictors of fatigue in patients with COPD. BMC Pulm Med. 2009;9:47.

6. Theander K, Jakobsson P, Torstensson O, Unosson M. Severity of fatigue is related to functional limitation and health in patients with chronic obstructive pulmonary disease. Int J Nurs Pract. 2008;14(6): 455-462.

7. Nguyen HQ, Donesky-Cuenco D, Carrieri-Kohlman V. Associations between symptoms, functioning, and perceptions of mastery with global self-rated health in patients with COPD: a cross-sectional study. Int $J$ Nurs Stud. 2008;45(9):1355-1365.

8. Paddison JS, Effing TW, Quinn S, Frith PA. Fatigue in COPD: association with functional status and hospitalisations. Eur Respir J. 2013; 41(3):565-570.

9. Leidy NK. Functional status and the forward progress of merry-go-rounds: toward a coherent analytical framework. Nurs Res. 1994;43(4): 196-202.

10. Breslin E, van der Schans C, Breukink S, et al. Perception of fatigue and quality of life in patients with COPD. Chest. 1998;114(4):958-964.

11. Belza B, Steele BG, Hunziker J, Lakshminaryan S, Holt L, Buchner DM. Correlates of physical activity in chronic obstructive pulmonary disease. Nurs Res. 2001;50(4):195-202.

12. Breukink SO, Strijbos JH, Koorn M, Koëter GH, Breslin EH, van der Schans CP. Relationship between subjective fatigue and physiological variables in patients with chronic obstructive pulmonary disease. Respir Med. 1998;92(4):676-682.

13. Baghai-Ravary R, Quint JK, Goldring JJ, Hurst JR, Donaldson GC, Wedzicha JA. Determinants and impact of fatigue in patients with chronic obstructive pulmonary disease. Respir Med. 2009;103(2):216-223.

14. Oh EG, Kim CJ, Lee WH, Kim SS. Correlates of fatigue in Koreans with chronic lung disease. Heart Lung. 2004;33(1):13-20.

15. Celli BR, Cote CG, Marin JM, et al. The body-mass index, airflow obstruction, dyspnea, and exercise capacity index in chronic obstructive pulmonary disease. $N$ Engl J Med. 2004;350(10):1005-1012.

16. Al-shair K, Kolsum U, Berry P, et al. Development, dimensions, reliability and validity of the novel Manchester COPD fatigue scale. Thorax. 2009;64(11):950-955.

17. Han MK, Postma D, Mannino DM, et al. Gender and chronic obstructive pulmonary disease: why it matters. Am J Respir Crit Care Med. 2007; 176(12):1179-1184.

18. de Torres JP, Casanova C, Hernández C, Abreu J, Aguirre-Jaime A, Celli BR. Gender and COPD in patients attending a pulmonary clinic. Chest. 2005;128(4):2012-2016. 
19. de Torres JP, Casanova C, Hernández C, et al. Gender associated differences in determinants of quality of life in patients with COPD: a case series study. Health Qual Life Outcomes. 2006;4:72.

20. Janaudis-Ferreira T, Wadell K, Sundelin G, Lindström B. Thigh muscle strength and endurance in patients with COPD compared with healthy controls. Respir Med. 2006;100(8):1451-1457.

21. Lacasse Y, Martin S, Lasserson TJ, Goldstein RS. Meta-analysis of respiratory rehabilitation in chronic obstructive pulmonary disease. A Cochrane systematic review. Eura Medicophys. 2007;43(4): 475-485.

22. Watson L, Schouten JP, Löfdahl CG, Pride NB, Laitinen LA, Postma DS; European Respiratory Society Study on Chronic Obstructive Pulmonary Disease. Predictors of COPD symptoms: does the sex of the patient matter? Eur Respir J. 2006;28(2):311-318.

23. de Torres JP, Casanova C, Montejo de Garcini A, Aguirre-Jaime A, Celli BR. Gender and respiratory factors associated with dyspnea in chronic obstructive pulmonary disease. Respir Res. 2007;8(1):18.

24. Theander K, Unosson M. Fatigue in patients with chronic obstructive pulmonary disease. J Adv Nurs. 2004;45(2):172-177.

25. Theander K, Unosson M. No gender differences in fatigue and functional limitations due to fatigue among patients with COPD. J Clin Nurs. 2011;20(9-10):1303-1310.

26. Portenoy RK, Thaler HT, Kornblith AB, et al. The Memorial Symptom Assessment Scale: an instrument for the evaluation of symptom prevalence, characteristics and distress. Eur J Cancer. 1994;30A(9):1326-1336.

27. Brusasco V, Crapo R, Viegi G; American Thoracic Society; European Respiratory Society. Coming together: the ATS/ERS consensus on clinical pulmonary function testing. Eur Respir J. 2005;26(1):1-2.

28. Hedenstrom H, Malmberg P, Agarwal K. Reference values for lung function tests in females. Regression equations with smoking variables. Bull Eur Physiopathol Respir. 1985;21(6):551-557.

29. Hedenström H, Malmberg P, Fridriksson HV. Reference values for lung function tests in men: regression equations with smoking variables. Ups J Med Sci. 1986;91(3):299-310.

30. Rabe KF, Hurd S, Anzueto A, et al; Global Initiative for Chronic Obstructive Lung Disease. Global strategy for the diagnosis, management, and prevention of chronic obstructive pulmonary disease: GOLD executive summary. Am J Respir Crit Care Med. 2007;176(6):532-555.

31. ATS Committee on Proficiency Standards for Clinical Pulmonary Function Laboratories. ATS statement: guidelines for the six-minute walk test. Am J Respir Crit Care Med. 2002;166(1):111-117.

32. Troosters T, Gosselink R, Decramer M. Six minute walking distance in healthy elderly subjects. Eur Respir J. 1999;14(2):270-274.

33. Borg GA. Psychophysical bases of perceived exertion. Med Sci Sports Exerc. 1982;14(5):377-381.
34. Nordenskiöld UM, Grimby G. Grip force in patients with rheumatoid arthritis and fibromyalgia and in healthy subjects. A study with the Grippit instrument. Scand J Rheumatol. 1993;22(1):14-19.

35. Csuka M, McCarty DJ. Simple method for measurement of lower extremity muscle strength. Am J Med. 1985;78(1):77-81.

36. Bestall JC, Paul EA, Garrod R, Garnham R, Jones PW, Wedzicha JA. Usefulness of the Medical Research Council (MRC) dyspnoea scale as a measure of disability in patients with chronic obstructive pulmonary disease. Thorax. 1999;54(7):581-586.

37. World Health Organization. ICF Checklist. Appendix 1 Brief Health Information. Geneva: World Health Organization; 2003. Available from: http://www.who.int/classifications/icf/training/icfchecklist.pdf. Accessed October 10, 2012.

38. Lenz ER, Suppe F, Gift AG, Pugh LC, Milligan RA. Collaborative development of middle-range nursing theories: toward a theory of unpleasant symptoms. ANS Adv Nurs Sci. 1995;17(3):1-13.

39. Cella D, Lai JS, Stone A. Self-reported fatigue: one dimension or more? Lessons from the Functional Assessment of Chronic Illness Therapy - Fatigue (FACIT-F) questionnaire. Support Care Cancer. 2011;19(9):1441-1450.

40. Naberan K, Azpeitia A, Cantoni J, Miravitlles M. Impairment of quality of life in women with chronic obstructive pulmonary disease. Respir Med. 2012;106(3):367-373.

41. Piper BF. Fatigue. In: Carrieri-Kohlman V, Lindsey AM, West CM, editors. Pathophysiological Phenomena in Nursing. 3rd ed. St Louis: Saunders; 2003:219-234.

42. Troosters T, Casaburi R, Gosselink R, Decramer M. Pulmonary rehabilitation in chronic obstructive pulmonary disease. Am J Respir Crit Care Med. 2005;172(1):19-38.

43. Rondelli RR, Dal Corso S, Simões A, Malaguti C. Methods for the assessment of peripheral muscle fatigue and its energy and metabolic determinants in COPD. J Bras Pneumol. 2009;35(11):1125-1135.

44. Torres SH, Montes de Oca M, Loeb E, Mata A, Hernández N. Gender and skeletal muscle characteristics in subjects with chronic obstructive pulmonary disease. Respir Med. 2011;105(1):88-94.

45. Skumlien S, Haave E, Morland L, Bjørtuft O, Ryg MS. Gender differences in the performance of activities of daily living among patients with chronic obstructive pulmonary disease. Chron Respir Dis. 2006;3(3):141-148.

46. Puhan MA, Schünemann HJ, Frey M, Scharplatz M, Bachmann LM. How should COPD patients exercise during respiratory rehabilitation? Comparison of exercise modalities and intensities to treat skeletal muscle dysfunction. Thorax. 2005;60(5):367-375.

47. Gift AG, Shepard CE. Fatigue and other symptoms in patients with chronic obstructive pulmonary disease: do women and men differ? J Obstet Gynecol Neonatal Nurs. 1999;28(2):201-208.
International Journal of COPD

\section{Publish your work in this journal}

The International Journal of COPD is an international, peer-reviewed journal of therapeutics and pharmacology focusing on concise rapid reporting of clinical studies and reviews in COPD. Special focus is given to the pathophysiological processes underlying the disease, intervention programs, patient focused education, and self management protocols.

\section{Dovepress}

This journal is indexed on PubMed Central, MedLine and CAS. The manuscript management system is completely online and includes a very quick and fair peer-review system, which is all easy to use. Visit http://www.dovepress.com/testimonials.php to read real quotes from published authors. 